\title{
Effect of Endogenous and Exogenous variables on Customer behavioural intention in Adoption of Digital Banking Services- A Technology Acceptance Model Study in the State of Telangana
}

\author{
John Paul. M \\ Research Scholar \\ Department of Management Studies \\ UCC\&BM, Mahatma Gandhi University, \\ Nalgonda \\ jpmennakanti@gmail.com
}

\author{
Dr. Ravi Aluvala \\ Associate Professor \\ Department of Management Studies \\ UCC\&BM, Mahatma Gandhi university. \\ Nalgonda. \\ aravi13371@gmail.com
}

\begin{abstract}
:
Technological Innovations and advancement in Information and communication technology have shown massive growth across the industries including Banking. With internet of things the stringent and Traditional method of Banking has seen a complete metamorphosis from time to time. This has facilitated the customer to have all their banking services at their fingertips without visiting physical banking outlets with their mobile gadgets. It reduces customer's fatigue of standing in longer queues, reduces transaction costs and time saving. The mere advancement of Technology cannot transform the entire process. There are other factors like extraneous variables or other behavioural related factors which drive the customers towards the adoption of the Digital Technologies. Moreover, the technologies which are vulnerable while dealing with financial related activities. Hence, the present study is an attempt to examine the Endogenous and Exogenous variables and their influence on Perceived Usefulness and Perceived Ease of Use which intern will influence Behavioural Intention to drive towards actual usage of Digital Technologies in Banking. The Present Study examines opinion of 686 respondents across the Telangana state by using E-TAM introduced by Venkatesh and Bala.
\end{abstract}

Key Words: Digital Banking, Behavioural Intention, E-TAM Model, Adoption and Digital Technologies.

\section{Introduction:}

This mechanism, over a period of time, lead to inherently inefficient and broken the customers and banking staff in dissatisfaction and increased costs. The banks need to re-engineer and redesign their platforms to build channels through digital Technologies. Customers expect increased dynamism at frond end. The Existing Banking systems are centralised in its operations and traditional in nature and leading to potential delays in implementing the changes in Banking system. The banks should focus on decoupling its existing monolithic approach to compete with core concept of Digital only banking approach (Newman, Sam-2015). Banks should alter their processes through financial re-engineering through technologies.

The existing Data policies in Banking are rigid and have no access to third party until now. Banks did not require any data to share with their competitors or other service providers in banking collaborations. Some banks used their data to improve their product and services. 
However, the Digitalisation of Banking sector requires to share data base with third party in providing better Digi banking services to its customers. The same was experienced by the European banks in data sharing with the consent of the Customers (O'Flaherty, $\boldsymbol{K}$. W., et al.).

Technology driven banking sector requires "one size fit all" approach by facilitating varied options and recommending diversified products to the customers in bigger scale, the financial diffusion and reduced interactions by using data to provide personalised customer experience in banking services (Allen, $\boldsymbol{F}$., $\boldsymbol{G} \boldsymbol{u}, \boldsymbol{X}$., \& Jagtiani, J.). Service providers analyse by integrating various sets of recorded data pertinent to customer like demographic, transaction, interaction, behaviour and application usage etc. Banks can provide and create unique experience to its customers. At the same time customers also expect the privacy, security, trust, perceived advantage, perceived use and cared interactions while dealing with digital channels.

Digital infrastructure, internet of things, digital awareness and a model of digital frame work are prerequisites for Digitalisation of Banking services. The government policy should also facilitate in promoting digital services to its customers. The services providers of Digital banking products should address risk management and provide trust and other security related matters to its customers to adapt Digital Banking Services.

\section{Objectives of the study:}

The present study focus to examine

1. To study the Endogenous and Exogenous Variables that influence Perceived Ease of Use and Perceived Usefulness.

2. To study Behavioural Intention of the customers in adopting Digital Technologies in Banking Sector.

\section{Hypotheses:}

$\mathrm{H}_{01}$ : Endogenous and Exogenous variables have positive impact on PU and PEU.

$\mathrm{H}_{02}$ : PU and PEU has positive influence on Behavioral Intention.

$\mathrm{H}_{03}$ : Behavioral Intention has positive influence on Actual Digital Usage in Banking.

\section{Preparation of data screening for the analysis:}

The researchers collected data by employing questionnaire and survey method. The data sets are to be screened prior to the analysis for finding if there is any missing values in the data sets, outliers, finding data rage if there is any deviation from the prescribed range, checking data for normality and conduct of Multi-Collinearity to make statistical analysis effective (Garson, $2015)^{1}$.

\section{Analysis of missing data and conduct of imputation:}

The researcher employed SPSS software to find the missing values in the Data set. The Univariate Statistics is performed for the quantitative variables and categorical variables in the analysis to identify missing values. The analysis revealed that the data has very less percentage of missing values which is less than $1 \%$ for the Item. 
The total number of Items which has missing data is only nine in the data set under the study. The little's MCAR test is conducted to find weather the values are missing completely at random (Little, R. J., \& Rubin, D. B. 1989)2. The test has shown that the Chi-square value is 873.144 , df -824 and significance value $=.114$ for 686 sample data. Since the test significance value is greater than 0.05 which means that the data missing is completely at Random. In order to replace missing values, the researcher has used widely prevailing and accepted method that is multiple imputation analysis (Van Buuren, S. 2012) ${ }^{3}$.

While conducting Multiple imputation analysis, the bootstrapping value is taken as 5 for the simulation and automatic method i.e., Markov Chain Monte Carlo (MCMC) simulation methods to predict and replace the missing values for the analysis (Garson, G. D. 2015) ${ }^{4}$. The missing values for the Items SN1, SN2, SN3, IUE5, TRU1, TRU2, TRU3, BK1 and BK2 are assigned.

\section{Testing data for Outliers:}

The researcher has used Mahalanobis Distance method to identify the values which are farthest from the Centroid value from the data by finding Mahalanobis D-square value. The multivariate outliers are identified by considering the $\mathrm{P}_{1}$ and $\mathrm{P}_{2}$ values which are up to less than 0.05 . However, the criteria for deletion of those outlier are permitted less than $10 \%$ of total sample collected (Yuan, K.-H., \& Zhong, X. 2013) ${ }^{5}$. The study under the consideration has values as per criteria to fit the model. Since data is having multivariate outliers it is very difficult for the researcher to delete all the outliers. Whenever the outliers are removed, additionally new outliers will be identified in case of data having multivariate outliers in this case the researchers used Mahalanobis method (Jarrell, M. G. 1994) ${ }^{6}$.

\section{Conduct of Normality Test:}

There are two main statistical tests to measure the normality i.e. Skewness and Kurtosis are to be tested weather, the data is normal or not. To find the data is symmetric or asymmetric, the statistical measure Skewness is used. The tool kurtosis is used to find the weather data measures heavy tailed or light tailed relative to normality of distribution. The measurement criteria for the normality to fit the model, the skewness value is determined to be less than three and the Kurtosis is less than the three times of the standard error preferred (Sposito et al., 1983) ${ }^{7}$. The above which these values are considered to be not a good fit for model (Stevens, J. P. 2009) ${ }^{8}$ (Westfall, P. H., \& Henning, K. S. S. 2013) ${ }^{9}$. The annexure is attached to show the values of skewness and Kurtosis of the present study.

\section{Test for Validity and Reliability:}

The researcher has conducted Convergent Validity and Discriminant Validity to ensure Construct Validity while conducting CFA for SEM analysis. The study employed master validity test by using AMOS plugin to obtain the CR, AVE, MSV and correlation table values developed by James Gaskin ${ }^{10}$. This ensures that the factors under the study demonstrate adequate reliability and validity for testing the SEM model. 


\section{Composite Reliability Test:}

In order to Test the Internal Scale Consistency, the Researcher has used Composite reliability test for the SEM analysis model. Composite reliability is the which sometimes referred as construct reliability measures the Internal Consistency of the scale used for CFA. It is similar to Cronbach's alpha which tests in case of Exploratory Factor analysis (Netemeyer, 2003) ${ }^{11}$. It explains variance between the total amount of true score variance compared to the total scale score Variance (Brunner \& Süß, 2005) ${ }^{12}$. Otherwise, it is the indicator which explains the shared variance between the Observed variables employed as an Indicator of a latent construct (Fornell \& Larcker, 1981) ${ }^{13}$.

The Thresholds for testing of Composite Reliability for CFA is 0.70 is said to be good reliability with $0.50 \mathrm{AVE}$, values anywhere from 0.60 to above are also considered to be reasonable. It is also debatable as different authors have suggested different values for the same. However, it is considered that the smaller the value the lower will be the Reliability level and larger the Composite reliability value the higher Reliability. The values above 0.95 are also considered to be not necessarily good as it is an indication of redundancy of the scale (Hulin, Netemeyer, and Cudeck, 2001) ${ }^{14}$.

The following table is the measure of Composite Reliability used for testing of thresholds for evaluating internal consistence of the scale employed for the SEM analysis.

\begin{tabular}{|l|l|}
\hline CONSTRUCT & $\begin{array}{l}\text { COMPOSITE RELIABILITY(CR) } \\
\text { VALUE }\end{array}$ \\
\hline Perceived Usefulness & 0.900 \\
\hline Perceived Ease of Use & 0.895 \\
\hline Accessibility & 0.834 \\
\hline Behavioural Intention & 0.836 \\
\hline Risk & 0.823 \\
\hline Compatibility & 0.894 \\
\hline Trialibility & 0.831 \\
\hline Availability & 0.712 \\
\hline Trust & 0.881 \\
\hline Internet Usage Efficacy & 0.905 \\
\hline Social Norms & 0.849 \\
\hline Govt. Initiatives & 0.913 \\
\hline Bank Promotion & 0.875 \\
\hline Actual Digital Usage & 0.851 \\
\hline Awareness & 0.861 \\
\hline
\end{tabular}


The table above shows the Composite reliability values for the constructs used in the analysis. As per the thresholds prescribed the CR values are greater than 0.70 for all the constructs, which is considered to be good reliability for the Internal Consistency of the Scale for the study.

\section{Convergent Validity}

The Average Variance Extracted (AVE) is used to test convergent validity. The convergent validity is sub part of the construct validity. Where construct validity measures the construct to ensure whether the construct is actually measuring the same purpose or not. The Convergent validity takes two measure and ensures that if the construct measure same and are related. The AVE is greater than 0.5 for all the constructs under the study. The AVE is considered to be strict measurement which explains the convergent validity. According to Malhotra and Dash (2011) "AVE is a more conservative measure than CR. On the basis of CR alone, the researcher may conclude that the convergent validity of the construct is adequate, even though more than $50 \%$ of the variance is due to error." (Malhotra and Dash, 2011, p.702) (5) $^{15}$.

\begin{tabular}{|l|l|}
\hline CONSTRUCT & $\begin{array}{l}\text { AVERAGE } \\
\text { EXPLAINED(AVE) }\end{array}$ \\
\hline Perceived Usefulness & 0.600 \\
\hline Perceived Ease of Use & 0.681 \\
\hline Accessibility & 0.558 \\
\hline Behavioural Intention & 0.562 \\
\hline Risk & 0.699 \\
\hline Compatibility & 0.585 \\
\hline Trialibility & 0.552 \\
\hline Availability & 0.553 \\
\hline Trust & 0.653 \\
\hline Internet Usage Efficacy & 0.615 \\
\hline Social Norms & 0.653 \\
\hline Govt. Initiatives & 0.779 \\
\hline Bank Promotion & 0.700 \\
\hline Actual Digital Usage & 0.741 \\
\hline Awareness & 0.756 \\
\hline
\end{tabular}

From the above table it is evident that all the values are above 0.50 for the construct under the study and as per the thresholds the study has fulfilled convergent validity to proceed for CFA.

\section{Discriminant Validity:}

Discriminant validity is a measure which tests the uncorrelated or how distinct is the factors under the study. The discriminant validity is tested by using Maximum shared variance which supposed to be less than the AVE for testing validity analysis. Discriminant Validity is 
achieved if the MSV or Average shared squared variance(ASV) is less than the Average Variance Extracted. In general, the AVE is considered to be strict measurement which explains the convergent validity, it is stated that "AVE is a more conservative measure than CR. On the basis of CR alone, the researcher may conclude that the convergent validity of the construct is adequate, even though more than $50 \%$ of the variance is due to error." (Malhotra and Dash, 2011, p.702) ${ }^{16}$. To assess the Discriminant Validity Fornell and Larckers approach is used where AVE of each construct supposed to be higher than the squared correlation between the construct and any other construct(Fornell and Larcker, 1981 $)^{17}$. The table also shows the $\operatorname{MaxR}(\mathrm{H})$ which is Maximum reliability indicator. The Acceptable threshold of $\operatorname{MaxR}(\mathrm{H})$ is $>0.70$. It also called as McDonald construct reliability. "It shows he $\mathrm{H}$ coefficient which describes the relation between latent construct and the measured indicator. It is unaffected by the sign which an indicator carries in loadings, also draws information from all indicators in such a way that commensurate with their ability to reflect the construct"( Hancock and Mueller, $2001)^{18}$.

Table: Maximum Shared Variance and Maximum reliability indicators for Discriminant Validity.

\begin{tabular}{|l|l|l|}
\hline CONSTRUCT & MSV & MaxR(H) \\
\hline Perceived Usefulness & 0.593 & 0.901 \\
\hline Perceived Ease of Use & 0.616 & 0.896 \\
\hline Accessibility & 0.548 & 0.842 \\
\hline Behavioural Intention & 0.503 & 0.846 \\
\hline Risk & 0.096 & 0.823 \\
\hline Compatibility & 0.596 & 0.901 \\
\hline Trialibility & 0.541 & 0.832 \\
\hline Availability & 0.524 & 0.712 \\
\hline Trust & 0.607 & 0.900 \\
\hline Internet Usage Efficacy & 0.539 & 0.914 \\
\hline Social Norms & 0.398 & 0.864 \\
\hline Govt. Initiatives & 0.442 & 0.914 \\
\hline Bank Promotion & 0.645 & 0.877 \\
\hline Actual Digital Usage & 0.485 & 0.852 \\
\hline Awareness & 0.510 & 0.866 \\
\hline
\end{tabular}

From the above table it is ensured that, the MSV and $\operatorname{MaxR}(\mathrm{H})$ thresholds are fulfilled for the study to proceed with the analysis. The $\operatorname{MaxR}(\mathrm{H})$ coefficient indicators are above 0.70 as per the prescribed thresholds. And the MSV is less the AVE. 
Table: Correlation among constructs, AVE and Squared Inter-Construct Correlation matrix.

\begin{tabular}{|c|c|c|c|c|c|c|c|c|c|c|c|c|c|c|c|}
\hline & $\begin{array}{l}\mathbf{P} \\
\mathbf{U}\end{array}$ & $\begin{array}{l}\mathbf{P E} \\
\mathbf{U}\end{array}$ & $\begin{array}{l}\mathrm{AC} \\
\mathrm{C}\end{array}$ & $\begin{array}{l}\text { B } \\
\text { I }\end{array}$ & $\begin{array}{l}\text { RS } \\
\mathbf{K}\end{array}$ & $\begin{array}{l}\text { COM } \\
\mathbf{P}\end{array}$ & $\begin{array}{l}\text { TR } \\
\text { L }\end{array}$ & $\begin{array}{l}\text { AVA } \\
\text { I }\end{array}$ & $\begin{array}{l}\text { TR } \\
\mathbf{U}\end{array}$ & $\begin{array}{l}\text { IU } \\
\mathbf{E}\end{array}$ & $\begin{array}{l}\mathbf{S} \\
\mathbf{N}\end{array}$ & $\begin{array}{l}\text { G } \\
\text { I }\end{array}$ & $\begin{array}{l}\mathbf{B} \\
\mathbf{P}\end{array}$ & $\begin{array}{l}\mathbf{A D} \\
\mathbf{U}\end{array}$ & $\begin{array}{l}\mathbf{A W} \\
\mathbf{R}\end{array}$ \\
\hline PU & 0.775 & & & & & & & & & & & & & & \\
\hline PEU & 0.679 & 0.825 & & & & & & & & & & & & & \\
\hline ACC & 0.674 & 0.772 & 0.747 & & & & & & & & & & & & \\
\hline BI & 0.678 & 0.839 & 0.712 & $\begin{array}{l}0.74 \\
9\end{array}$ & & & & & & & & & & & \\
\hline RSK & 0.132 & 0.167 & 0.163 & $\begin{array}{l}0.21 \\
3\end{array}$ & 0.836 & & & & & & & & & & \\
\hline $\begin{array}{l}\mathrm{CO} \\
\mathrm{M}\end{array}$ & 0.701 & 0.703 & 0.804 & $\begin{array}{l}0.70 \\
2\end{array}$ & 0.094 & 0.765 & & & & & & & & & \\
\hline TRL & 0.662 & 0.662 & 0.676 & $\begin{array}{l}0.72 \\
2\end{array}$ & 0.310 & 0.699 & 0.743 & & & & & & & & \\
\hline $\begin{array}{l}\text { AVA } \\
\text { I }\end{array}$ & 0.695 & 0.686 & 0.715 & $\begin{array}{l}0.66 \\
5\end{array}$ & 0.244 & 0.735 & 0.638 & 0.743 & & & & & & & \\
\hline TRU & 0.726 & 0.779 & 0.680 & $\begin{array}{l}0.65 \\
5\end{array}$ & 0.000 & 0.713 & 0.529 & 0.581 & 0.808 & & & & & & \\
\hline IUE & 0.763 & 0.799 & 0.687 & $\begin{array}{l}0.70 \\
2\end{array}$ & 0.184 & 0.772 & 0.644 & 0.635 & 0.711 & 0.785 & & & & & \\
\hline SN & 0.572 & 0.593 & 0.563 & $\begin{array}{l}0.57 \\
9\end{array}$ & 0.239 & 0.567 & 0.521 & 0.469 & 0.524 & 0.595 & 0.808 & & & & \\
\hline GI & 0.586 & 0.665 & 0.556 & $\begin{array}{l}0.56 \\
2\end{array}$ & 0.210 & 0.584 & 0.524 & 0.526 & 0.619 & 0.615 & 0.631 & 0.882 & & & \\
\hline BP & 0.741 & 0.803 & 0.625 & $\begin{array}{l}0.74 \\
2\end{array}$ & 0.216 & 0.758 & 0.606 & 0.577 & 0.646 & 0.679 & 0.561 & 0.626 & 0.837 & & \\
\hline $\mathrm{ADU}$ & 0.658 & 0.697 & 0.619 & $\begin{array}{l}0.68 \\
9\end{array}$ & 0.113 & 0.692 & 0.614 & 0.581 & 0.604 & 0.658 & 0.492 & 0.530 & 0.623 & 0.861 & \\
\hline $\begin{array}{l}\text { AW } \\
\text { R }\end{array}$ & 0.635 & 0.714 & 0.591 & $\begin{array}{l}0.68 \\
6\end{array}$ & 0.169 & 0.652 & 0.584 & 0.545 & 0.639 & 0.623 & 0.536 & 0.585 & 0.679 & 0.602 & 0.870 \\
\hline
\end{tabular}

The table above shows the values corresponding to the AVE that are being highlighted in block letters. The values in diagonal indicates correlations of the construct and the corresponding values are square pf correlations between the correlations obtained using the master validity plugins from Gaskins from AMOS software (Gaskin, J., \& Lim, J. 2016) ${ }^{19}$.it is stated that if AVE is higher than the square of the inter construct correlation for each construct then it is considered that the discriminant validity is supported(Farrell, A. M. $(2010)^{20}$. In the above fore mentioned model the master validity table shows that the Discriminant validity is established for the Model.

\section{Testing of Model fit Indices for Confirmatory Factor Analysis for SEM:}

The model fit indices for goodness of fit for CFA model measures are stated as per the determinants calculated and the threshold are given below ( $\mathrm{Hu}$ and Bentler 1999). ${ }^{21}$ The detailed thresholds with contextualized guidelines are stated in Hair et al 201022. The 
standardized measures and their threshold i.e., Chi- Square/df (cmin/df) is $<3$ good; < 5is sometimes permissible. The p-value for the model should be $>0.05$. CFI values $>0.95$ is considered to be great, $>0.90$ traditional; and $>0.80$ is sometimes permissible as the constructs under the study are large. GFI value is considered to be $>0.95$ while AGFI is $>0.80$ as per the base line model (Kaplan, 2000) ${ }^{23}$. However, this is not same for all circumstances to have goodness of fit indices greater than the baseline model. As the sample size varies and number of constructs in the model increase the prescribed indices change for Goodness of fit $(\mathrm{Hu} \&$ Bentler, 1995, p. 95) ${ }^{24}$. The threshold values for badness of fit SRMR $<0.09$ and RMSEA $<0.05$ is considered to be good, 0.05 to 0.10 is moderate and $>.10$ is considered to be Bad fit. The incremental fit indices IFI $>0.9$ and TLI $>0.9$. Aforesaid indices of the model change when the model has complexity and sample more than 250 size and the achievement of goodness of fit varies with CFI (Hair et al 2010) ${ }^{25}$.

\section{The Measurement Model fit Indices for testing Conceptual TAM Under the Study (Initial Untrimmed model):}

The study employed maximum likelihood estimation for assessing CFA for the model test. The ML method estimation, Standardized estimates and Modification Indices were used to calculate model parameters to assess the CFA model fit. The Estimated values of base model under the study are given below.

The Model has $\chi^{2}=4753.010, \mathrm{df}=1627, \mathrm{p}=.000$ and the $\mathrm{CMIN} / \mathrm{df}$ i.e. $\chi^{2} / \mathrm{df}=2.921$, The model tested RMR value as $0.056, \mathrm{GFI}=0.802$, $\mathrm{AGFI}=0.770$. The baseline comparisons of the model $\mathrm{IFI}=0.894, \mathrm{TLI}=0.880, \mathrm{CFI}=0.893$ and RMSEA $0.054, \mathrm{PCLOS}=0.000$. The Untrimmed model has some of the goodness of the fit indices below the prescribed level of measurement. Hence, the researcher has gone for redefining and model trimming to better fit the model.

\section{Refinement of Model trimming for improving Measurement Indices:}

The study focused on improving the model by calculating modification indices. The study has identified regression weights less than 0.7 and factor loading which are less than 0.5 are identified and deleted from the model to get model fit indices improve. The constructs like RK3, INT1, INT2, UE1, and UE2 are removed from the model to improve model fit indices. The study also used 'connecting of error' terms to improve the model fit. The following are the values of trimmed model. The trimmed Model has $\chi^{2}=3635.125, \mathrm{df}=1319, \mathrm{p}=.000$ and the $\mathrm{CMIN} / \mathrm{df}$ i.e. $\chi^{2} / \mathrm{df}=2.756$. The model tested $\mathrm{RMR}$ value as $0.044, \mathrm{GFI}=0.898, \mathrm{AGFI}=0.880$. The baseline comparisons of the model IFI $=0.914$, TLI $=0.903, \mathrm{CFI}=0.914$ and RMSEA 0.051. PCLOSE $=0.021$ The Untrimmed model has most of the goodness of the fit indices below the values. Hence, the researcher has gone for redefining and model trimming to better fit the model.

The model above has fulfilled the criterion for goodness of fit for CFA to proceed for Structural Equation Model to fit ETAM model for the analysis. 


\section{Testing Hypothesized Causal relationship of Structural Model for Conceptual TAM Path analysis:}

The figure below shows the testing of Conceptual model developed based on TAM3, TAM-3 is an integrated model which explains the individual level acceptance of Technology adoption and its use. This model is developed by Venkatesh and Bala by considering their own construct of TAM2 (Venkatesh \& Davis) ${ }^{26}$ with combining the actor determinant perceived ease of use and Perceived usefulness on Customers behavioural Intention(Venkatesh) ${ }^{27}$. This model includes independent variables and dependent variables and measures the impact of those variables influencing the Behavioural Intention of the Individuals in adopting the Digital Technologies in Banking Sector(FinTech).

The present model has taken the variables i.e. Risk, Trust, Govt. Initiatives, Bankers promotion, Awareness, Social Influence and Internet Usage efficacy on the variables Perceived Usefulness and Perceived Ease of Use which intern will reflect on Behavioral Intention of the Individuals to drive towards actual usage of system. On the other hand, the study also focused on testing of variables like Compatibility of Technologies, Availability, Trialibility and Accessibility has any influence on the Perceived Ese of Use which in turn will reflect on the Behavioral intention to use Digital Technologies.

The figure below shows the path analysis of the Conceptual model developed based on the integrated TAM3 model developed by the Venkatesh and Bala.

\section{Conceptual Frame Work of TAM for Digital Technologies Acceptance in Banking Sector:}

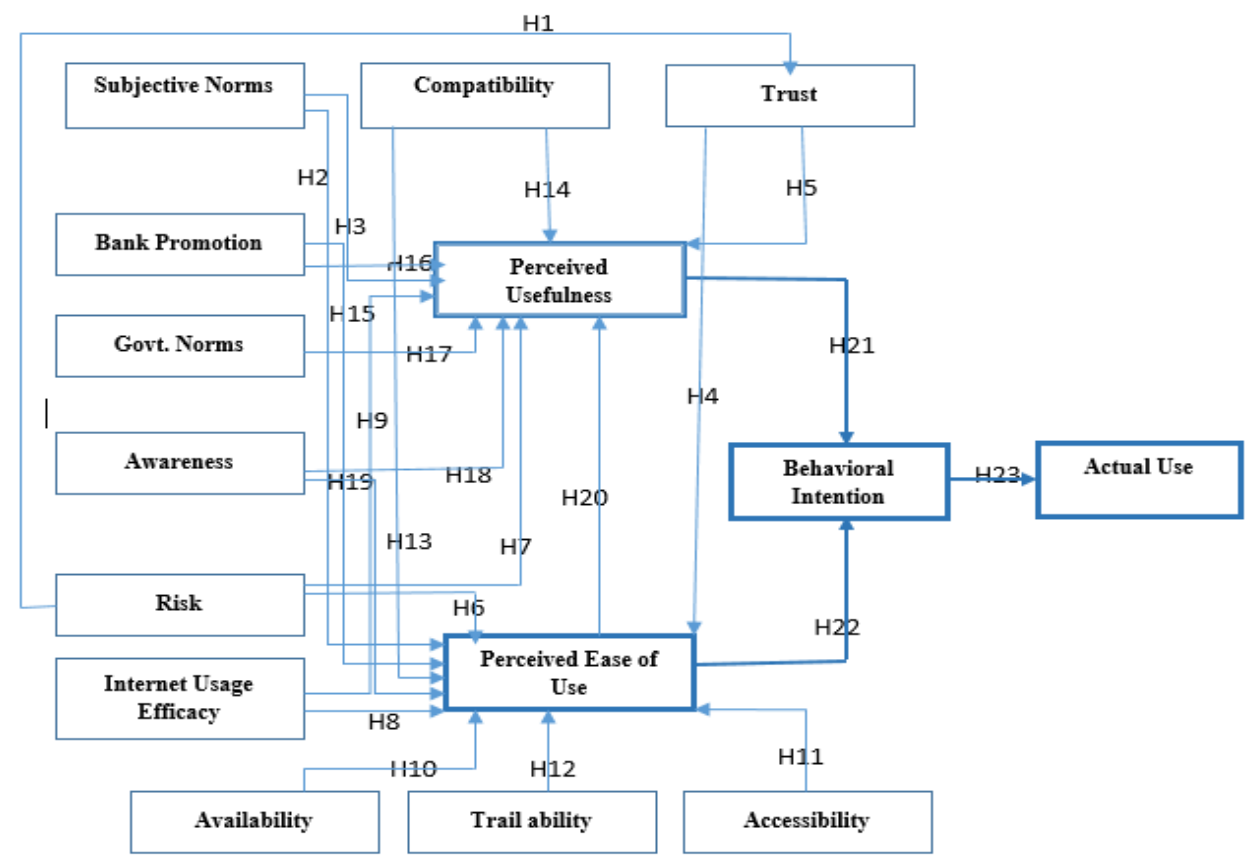

The figure above is the conceptual model Developed by taking the Venkatesh and Bala E-TAM model to study the present Technology acceptance level in Banking Sector. The Model incorporates the other variables like Availability, Accessibility, Awareness and Trialibilty etc., in to the model to study the influence of Exogenous variables on the Acceptance model. It considers the basic TAM with extended variables for the analysis under the Study. 
The Standard Regression weights calculated for the variables to test relation using ETAM Model.

\begin{tabular}{|l|l|l|l|l|l|l|l|}
\hline \multicolumn{2}{|c|}{ Path analysis relation } & Estimate & S.E. & C.R. & P-Value & Decision \\
\hline TRU & $<---$ & RK & .043 & .052 & .818 & .413 & Not Supported \\
\hline PEU & $<---$ & SN & .018 & .018 & 1.000 & .317 & Not Supported \\
\hline PU & $<---$ & SN & .048 & .021 & 2.280 & .023 & Supported \\
\hline PEU & $<---$ & TRU & .202 & .026 & 7.662 & $* * *$ & Supported \\
\hline PU & $<---$ & TRU & .121 & .033 & 3.701 & $* * *$ & Supported \\
\hline PEU & $<---$ & RK & .063 & .028 & 2.285 & .022 & Supported \\
\hline PU & $<---$ & RK & .015 & .032 & .452 & .651 & Not Supported \\
\hline PEU & $<---$ & IUE & .138 & .021 & 6.684 & $* * *$ & Supported \\
\hline PU & $<---$ & IUE & .109 & .026 & 4.192 & $* * *$ & Supported \\
\hline PEU & $<---$ & AVL & -.001 & .022 & -.068 & .946 & Not Supported \\
\hline PEU & $<---$ & ACC & .101 & .020 & 5.116 & $* * *$ & Supported \\
\hline PEU & $<---$ & TRL & .012 & .026 & .464 & .643 & Not Supported \\
\hline PEU & $<---$ & COM & .379 & .030 & 12.791 & $* * *$ & Supported \\
\hline PU & $<---$ & COM & .412 & .046 & 8.951 & $* * *$ & Supported \\
\hline PEU & $<---$ & BKP & .154 & .019 & 7.940 & $* * *$ & Supported \\
\hline PU & $<---$ & BKP & .083 & .025 & 3.343 & $* * *$ & Supported \\
\hline PU & $<---$ & GVT.P & .002 & .018 & .122 & .903 & Not Supported \\
\hline PEU & $<---$ & AWR & .113 & .020 & 5.590 & $* * *$ & Supported \\
\hline PU & $<---$ & AWR & -.024 & .024 & -.972 & .331 & Not Supported \\
\hline PU & $<---$ & PEU & .298 & .084 & 3.565 & $* * *$ & Supported \\
\hline BI & $<---$ & PU & .215 & .061 & 3.541 & $* * *$ & Supported \\
\hline BI & $<---$ & PEU & .656 & .083 & 7.871 & $* * *$ & Supported \\
\hline ADU & $<---$ & BI & .916 & .082 & 11.242 & $* * *$ & Supported \\
\hline
\end{tabular}

Estimates of the R Square Coefficient Value for the Dependent Variables:

The table below shows the $\mathrm{R}^{2}$ coefficient value for the Dependant variables perceived Ease of Use, Perceived Usefulness, Behavioural Intention and Actual System Usage for the conceptual Model under the study. The $\mathrm{R}^{2}$ value indicates the variance caused by the Independent variable on the Dependent Variable under the study. The $\mathrm{R}^{2}$ value indicates that high or Low in accordance with the use and context with which the regression model is developed.

\begin{tabular}{|l|l|}
\hline Dependent Variables & R Square Value \\
\hline Perceived Ease of Use & .907 \\
Perceived Usefulness & .888 \\
Behavioural Intention & .747 \\
Actual Digital System Usage & .528 \\
\hline
\end{tabular}




\section{Summary of Hypotheses testing using Path analysis:}

The path model established above shows the causal relationship between the Constructs the study adopted to test the Hypotheses.

\begin{tabular}{|c|c|c|}
\hline & Hypotheses Statement & Decision \\
\hline $\mathrm{H}_{1}$ & $\begin{array}{l}\text { Perceived Risk positively influences the Trust of the Individuals in } \\
\text { adopting the Digital Technologies in baking sector(Fintech). }\end{array}$ & Not Supported \\
\hline $\mathrm{H}_{2}$ & $\begin{array}{l}\text { Social Norms has positive influence on Perceived ease of Use in } \\
\text { adopting the Digital Technologies in baking sector(Fintech). }\end{array}$ & Not Supported \\
\hline $\mathrm{H}_{3}$ & $\begin{array}{l}\text { Social Norms has positive influence on Perceived Usefulness in } \\
\text { adopting the Digital Technologies in baking sector(Fintech). }\end{array}$ & Supported \\
\hline $\mathrm{H}_{4}$ & $\begin{array}{l}\text { Trust has positive influence on Perceived Ease of Use in adopting } \\
\text { the Digital Technologies in baking sector(Fintech). }\end{array}$ & Supported \\
\hline $\mathrm{H}_{5}$ & $\begin{array}{l}\text { Trust has positive influence on Perceived Usefulness in adopting } \\
\text { the Digital Technologies in baking sector(Fintech). }\end{array}$ & Supported \\
\hline $\mathrm{H}_{6}$ & $\begin{array}{l}\text { Perceived Risk negatively influences Perceived Ease of Use in } \\
\text { adopting the Digital Technologies in baking sector(Fintech). }\end{array}$ & Supported \\
\hline $\mathrm{H}_{7}$ & $\begin{array}{l}\text { Perceived Risk negatively influences Perceived Usefulness in } \\
\text { adopting the Digital Technologies in baking sector(Fintech). }\end{array}$ & Not Supported \\
\hline $\mathrm{H}_{8}$ & $\begin{array}{l}\text { Internet Usage efficacy has positive influence on Perceived Ease of } \\
\text { use in adopting the Digital Technologies in baking sector(Fintech). }\end{array}$ & Supported \\
\hline $\mathrm{H}_{9}$ & $\begin{array}{l}\text { Internet Usage efficacy has positive influence on Perceived } \\
\text { usefulness in adopting the Digital Technologies in baking } \\
\text { sector(Fintech). }\end{array}$ & Supported \\
\hline $\mathrm{H}_{10}$ & $\begin{array}{l}\text { The availability factor positively influences the PEU in adopting the } \\
\text { Digital Technologies in baking sector(Fintech). }\end{array}$ & Not Supported \\
\hline $\mathrm{H}_{11}$ & $\begin{array}{l}\text { Accessibility factor positively influences the PEU in adopting the } \\
\text { Digital Technologies in baking sector(Fintech). }\end{array}$ & Supported \\
\hline $\mathrm{H}_{12}$ & $\begin{array}{l}\text { Trial ability factor positively influences the PEU in adopting the } \\
\text { Digital Technologies in baking sector(Fintech). }\end{array}$ & Not Supported \\
\hline $\mathrm{H}_{13}$ & $\begin{array}{l}\text { Compatibility factor positively influences the PEU in adopting the } \\
\text { Digital Technologies in baking sector(Fintech). }\end{array}$ & Supported \\
\hline $\mathrm{H}_{14}$ & $\begin{array}{l}\text { Compatibility factor positively influences the PU in adopting the } \\
\text { Digital Technologies in baking sector(Fintech). }\end{array}$ & Supported \\
\hline $\mathrm{H}_{15}$ & $\begin{array}{l}\text { Banks promotions has positive influences on PEU in adopting the } \\
\text { Digital Technologies in baking sector(Fintech). }\end{array}$ & Supported \\
\hline $\mathrm{H}_{16}$ & $\begin{array}{l}\text { Banks promotions has positive influences on PU in adopting the } \\
\text { Digital Technologies in baking sector(Fintech). }\end{array}$ & Supported \\
\hline $\mathrm{H}_{17}$ & $\begin{array}{l}\text { Govt. initiatives has positive influences on PU in adopting the } \\
\text { Digital Technologies in baking sector(Fintech). }\end{array}$ & Not Supported \\
\hline $\mathrm{H}_{18}$ & $\begin{array}{l}\text { Awareness has positive influence on PU in adopting the Digital } \\
\text { Technologies in baking sector(Fintech) }\end{array}$ & Supported \\
\hline $\mathrm{H}_{19}$ & $\begin{array}{l}\text { Awareness has positive influence on PEU in adopting the Digital } \\
\text { Technologies in baking sector(Fintech). }\end{array}$ & Not Supported \\
\hline
\end{tabular}




\begin{tabular}{|l|l|l|}
\hline $\mathrm{H}_{20}$ & $\begin{array}{l}\text { Perceived Ease of Use has positive influence on Perceived } \\
\text { Usefulness in adopting the Digital Technologies in baking } \\
\text { sector(Fintech). }\end{array}$ & Supported \\
\hline $\mathrm{H}_{21}$ & $\begin{array}{l}\text { Perceived Usefulness has positive influence on Behavioral Intention } \\
\text { of individuals in adopting the Digital Technologies in baking } \\
\text { sector(Fintech). }\end{array}$ & Supported \\
\hline $\mathrm{H}_{22}$ & $\begin{array}{l}\text { Perceived Ease of Use has positive influence on Behavioral } \\
\text { Intention of individuals in adopting the Digital Technologies in } \\
\text { baking sector(Fintech). }\end{array}$ & Supported \\
\hline $\mathrm{H}_{23}$ & $\begin{array}{l}\text { Behavioral Intention has positive influence on Actual Digital Usage } \\
\text { of individuals in adopting the Digital Technologies in baking } \\
\text { sector(Fintech). }\end{array}$ & Supported \\
\hline
\end{tabular}

\section{Discussion and conclusion:}

From the above data it is evident that the Factors influencing adoption of Digital Technologies have significant impact on the Dependent variables like Perceived Ease of Use and Perceived Usefulness. It in turn, had resulted in Actual Digital Usage of Technologies in Banking Sector. The basic TAM Model which includes only PU, PEU on Behavioural Intention has shown that the Davis (1986) proposed model is significant and it can be accepted from the model is that the respondents are willing to accept the Technologies in Banking. However, the Study also made an attempt to understand the other exogenous and endogenous variables that have their influence on Perceived Ease of Use and Perceived Usefulness of the Technologies which reflects and impacts the Behavioural Intention of the Respondents in using of the Technologies. When tested different variables the Factor Social Norms, the Availability of Technologies, Trialibility factor have no positive impact on the Perceived Ease of Use. The factors like Risk, Government support and Awareness have not influenced the Perceived Usefulness of the Technologies in Banking. The study compared $\mathrm{R}^{2}$ value to measure the how well the Regression model is fit for the study made basing on the Beta Values. The $\mathrm{R}^{2}$ value for the Dependant variable Perceived Usefulness is .888 (88.8\%) which is considered as good interpreter that the variables have strong impact on the construct. The $\mathrm{R}^{2}$ value for the Dependant variable Perceived Ease of Use is .907 (90.7\%). It is strong explanation of the variance caused by Independent variables on the Perceived Ease of Use. For the construct Behavioural Intention the $\mathrm{R}^{2}$ value is .747 which indicates the $74.7 \%$ of variance is caused by the PU and PEU and Actual Digital Usage is .528. When compared to other variables for the construct Actual Digital Usage is significant but it is moderate where the 52.8\% only resulting in Actual Digital System Usage of technologies in the Banking Sector.

Finally, the study concludes that the respondents under the study has positive opinion which the factors indicates that the usage of Technologies have advantage. It is the good sign from the respondents which shows high level of variance that caused to Perceived Usefulness and Perceived Ease of Use of Technologies that drive Behavioural Intention of the respondents. However, the final adoption of the Technologies is not in same accordance with the positive opinion the Respondents. There is need to address certain issues which are restraining the respondents in resulting in Actual Usage. 


\section{References}

${ }^{1}$ Garson, G. D. (2015). Missing values analysis and data imputation. Asheboro, NC: Statistical Associates Publishers, 1-26.

${ }^{2}$ Little, R. J., \& Rubin, D. B. (1989). The analysis of social science data with missing values. Sociological Methods \& Research, 18(2-3), 292-326.

${ }^{3}$ Van Buuren, S. (2012) Flexible Imputation of Missing Data, Chapter 2. Multiple Imputation. Chapman and Hall/CRC Press, Boca Raton, 25-52.

${ }^{4}$ Garson, G. D. (2015). Missing values analysis and data imputation. Asheboro, NC: Statistical Associates Publishers, 1-26.

${ }^{5}$ Yuan, K.-H., \& Zhong, X. (2013). Robustness of Fit Indices to Outliers and Leverage Observations in Structural Equation Modeling. Psychological Methods, 18(2), 121-136. doi: 10.1037/a0031604

${ }^{6}$ Jarrell, M. G. (1994). A comparison of two procedures, the Mahalanobis Distance and the Andrews-Pregibon Statistic, for identifying multivariate outliers. Research in the schools, 1, 49-58.

7 Sposito, V. A., Hand, M. L., \& Skarpness, B. (1983). On the efficiency of using the sample kurtosis in selecting optimal lpestimators. Communications in Statistics-simulation and Computation, 12(3), 265-272.

${ }^{8}$ Stevens, J. P. (2009). Applied multivariate statistics for the social sciences (5th ed.). Mahwah, NJ: Routledge Academic.

${ }^{9}$ Westfall, P. H., \& Henning, K. S. S. (2013). Texts in statistical science: Understanding advanced statistical methods. Boca Raton, FL: Taylor \& Francis.

${ }^{10}$ Gaskin, J., James, M., \& Lim, J. (2016). AMOS plugin. Gaskination's StatWiki. Model fit measures.

${ }^{11}$ Netemeyer, R. G., Bearden, W. O., \& Sharma, S. (2003). Scaling procedures: Issues and applications. Sage Publications.

${ }^{12}$ Brunner, M., \& SÜ $\beta$, H. M. (2005). Analyzing the reliability of multidimensional measures: An example from intelligence research. Educational and Psychological Measurement, 65(2), 227-240.

${ }^{13}$ Fornell, C. \& Larcker, D. (1981). Evaluating Structural Equation Models with Unobservable Variables and Measurement Error. Journal of Marketing Research Vol. 18, No. 1 (Feb), pp. 39-50.

${ }^{14}$ Hulin, C., Netemeyer, R., \& Cudeck, R. (2001). Can a reliability coefficient be too high?. Journal of Consumer Psychology, 55-58.

${ }^{15}$ Malhotra N. K., Dash S. (2011). Marketing Research an Applied Orientation. London: Pearson Publishing.

${ }^{16}$ Malhotra N. K., Dash S. (2011). Marketing Research an Applied Orientation. London: Pearson Publishing.

17 Fornell, C., \& Larcker, D. F. (1981). Evaluating structural equation models with unobservable variables and measurement error. Journal of marketing research, 18(1), 39-50.

${ }^{18}$ Hancock, G. R., \& Mueller, R. O. (2001). Rethinking construct reliability within latent variable systems. Scientific Software International, Inc., USA.

${ }^{19}$ Gaskin, J., \& Lim, J. (2016). Master validity tool. AMOS Plugin In: Gaskination's StatWiki.

${ }^{20}$ Farrell, A. M. (2010). Insufficient discriminant validity: A comment on Bove, Pervan, Beatty, and Shiu (2009). Journal of business research, 63(3), 324-327. 
${ }^{21} \mathrm{Hu}$, L. T., \& Bentler, P. M. (1999). Cutoff criteria for fit indexes in covariance structure analysis: Conventional criteria versus new alternatives. Structural equation modeling: a multidisciplinary journal, 6(1), 1-55.

${ }^{22}$ Hair, J. F., Celsi, M., Ortinau, D. J., \& Bush, R. P. (2010). Essentials of marketing research (Vol. 2). New York, NY: McGraw-Hill/Irwin.

${ }^{23}$ Kaplan, D. (2000). Structural equation modeling: Foundation and extensions. Thousand Oaks, CA: Sage Publications.

${ }^{24} \mathrm{Hu}$, L., \& Bentler, P. (1995). Evaluating model fit. In R. H. Hoyle (Ed.), Structural equation modeling. Concepts, issues, and applications (pp. 76-99). London: Sage

25 IBID

${ }^{26}$ V. Venkatesh and F.D. Davis, "A theoretical extension of the technology acceptance model: Four longitudinal field studies", Management science, vol. 46, no. 2, (2000), pp. 186-204.

${ }^{27} \mathrm{~V}$. Venkatesh, "Determinants of perceived ease of use: Integrating control, intrinsic motivation, and emotion into the technology acceptance model", Information systems research, vol. 11, no. 4, (2000), pp. 342-365. 